\begin{tabular}{|c|c|c|}
\hline 22 & $\begin{array}{l}\text { Припаиваем вход блока питания к разъему } 220 \\
\text { вольт через выключатель. }\end{array}$ & $\begin{array}{l}\text { Верстак, паяльник, } \\
\text { припой, паяльная кислота, } \\
\text { кусачки }\end{array}$ \\
\hline 23 & $\begin{array}{l}\text { Припаиваем провода питания кулера к выходу } 12 \\
\text { вольт на блоке питания. }\end{array}$ & $\begin{array}{l}\text { Верстак, паяльник, } \\
\text { припой, паяльная кислота, } \\
\text { кусачки }\end{array}$ \\
\hline 24 & $\begin{array}{l}\text { Подключаем все разъемы и шлейф к блоку } \\
\text { питания. }\end{array}$ & Верстак \\
\hline 25 & $\begin{array}{l}\text { Прикручиваем винтами боковые стенки к пластине } \\
\text { ПВХ с блоком питания при помощи металлических } \\
\text { уголков. }\end{array}$ & Верстак, отвертка \\
\hline 26 & $\begin{array}{l}\text { Прикручиваем винтами фронтальную и тыловую } \\
\text { стенки к полученной конструкции при помощи } \\
\text { металлических уголков. }\end{array}$ & Верстак, отвертка \\
\hline 27 & $\begin{array}{l}\text { Для крепления верхней крышки установим } \\
\text { металлические уголки внутрь конструкции. } \\
\text { Устанавливаем крышку при помощи винтов. }\end{array}$ & $\begin{array}{lr}\text { Верстак, } & \text { шуруповерт, } \\
\text { сверло } & \text { диаметром } \\
\text { отвертка } & \end{array}$ \\
\hline
\end{tabular}

Сделанная мультифункциональная зарядная станция дает возможность подключения множества устройств, не прибегая к большому количеству зарядок и проводов. Также данный прототип дает возможность универсализировать процесс зарядки множества видов аккумуляторов с помощью одного устройства

Список литературы:

1. Электроника для начинающих. Автор: Чарльз Платт

2. http://radio-hobby.org/modules/news/article.php?storyid=264

3. https://ru.wikipedia.org/wiki/Зарядные устройства

4. https://ru.wikipedia.org/wiki/Аккумуляторы

\title{
Разработка информационной системы «Красная книга»
}

Жадько А.А., студент, Технический институт (филиал) Северо-Восточного федерального университета, 2. Нерюнгри E-mail: arxangel1310@mail.ru

Научный руководитель: к.т.н., доцент Похорукова М.Ю.

Красная книга - аннотированный список редких и находящихся под угрозой исчезновения животных, растений и грибов. Красная книга является основным документом, в котором обобщены материалы о современном состоянии редких и находящихся под угрозой исчезновения видов растений и животных, на основании которых проводится разработка научных и практических мер, направленных на их охрану, воспроизводство и рациональное использование [1]. 
Создание информационной системы, обеспечивающей автономную работу с электронной красной книгой, предполагает использование базы данных для поддержки таких операций как ввод, хранение, изменение, удаление, поиск и пр. Такой подход отличается удобством и доступностью, поскольку можно получить необходимую информацию о животных, занесенных в красную книгу, быстро и в любое время.

На рис. 1 представлена структура базы данных, содержащая информацию о животных, категориях, отрядах, семействах, классах, а также выдаваемых в системе справках.

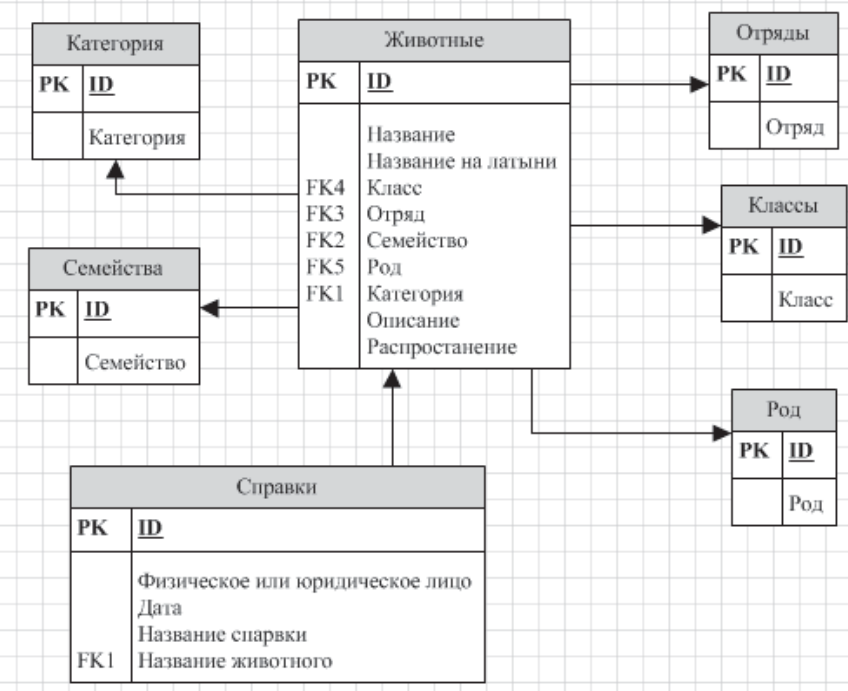

Рис. 1. База данных «Красная книга»

В процессе создания рассматриваемой информационной системы были сформулированы следующие требования к ее функциональности:

- простота при эксплуатации приложения;

- кроссплатформенность;

- поддержка целостности данных;

- минимальное время поиска, выдачи и обработки информации в БД.

В соответствии с этим в качестве программных средств для разработки приложения были выбраны: FireBird 2.5 для поддержки работы с базой данных и Embarcadero RAD Studio 2010, которая является 1комплексным решением для разработки различных приложений WINDOWS, БД, веб-приложений, .NET. в быстром режиме.

При запуске приложения «Красная книга» выводится главное окно (рис. 2). 


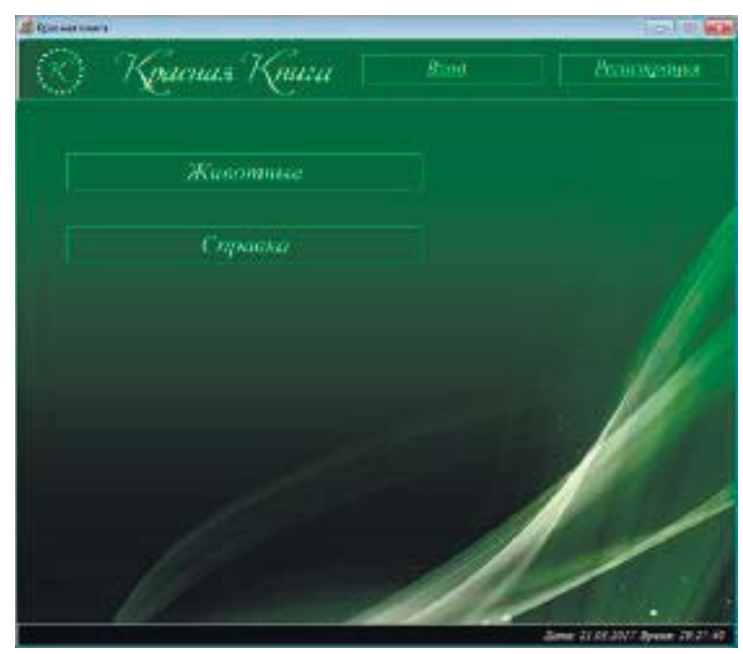

Рис. 2. Главное окно «Красная книга»

«Регистрация». При нажатии на данную кнопку появится новое окно (рисунок 3), в котором пользователя попросят ввести необходимые данные для того чтобы зарегистрироваться в приложении, если данные будут введены корректно, то пользователь зарегистрируется.

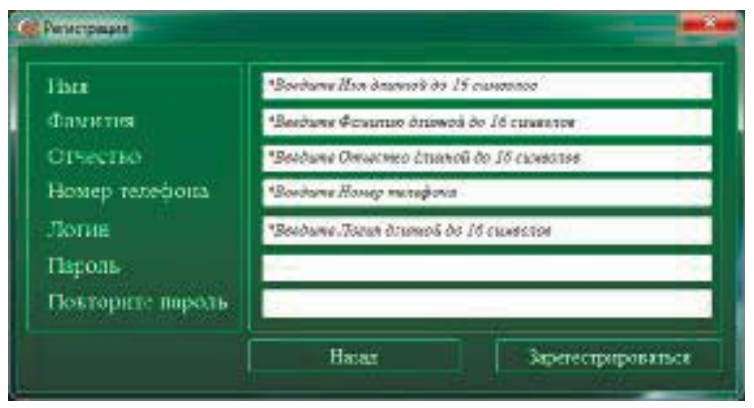

Рис. 3. Регистрация

«Войти». При нажатии на данную кнопку появится новое окно «Авторизация» (рисунок 4), в котором пользователя попросят ввести логин и пароль для аутентификации пользователя. Если пользователь зарегистрирован, знает свой логин и пароль, то он сможет войти в систему, иначе будет выведена ошибка о том, что логин и пароль введены неверно.

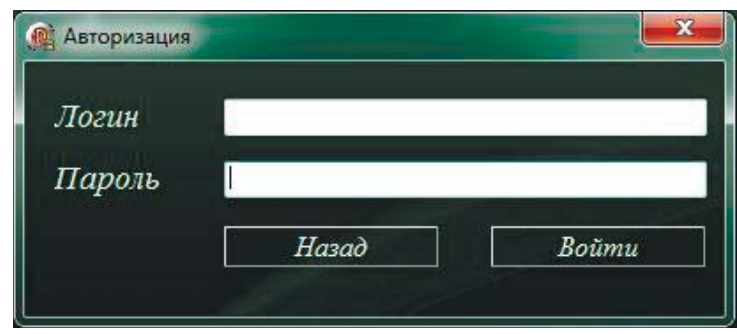

Рис. 4. Авторизация

Так же в главном окне можно увидеть кнопки:

При нажатии на «Животные» кнопку появится новое окно (рисунок 5), в котором пользователь может выбрать название животного и прочитать о нём информацию. 


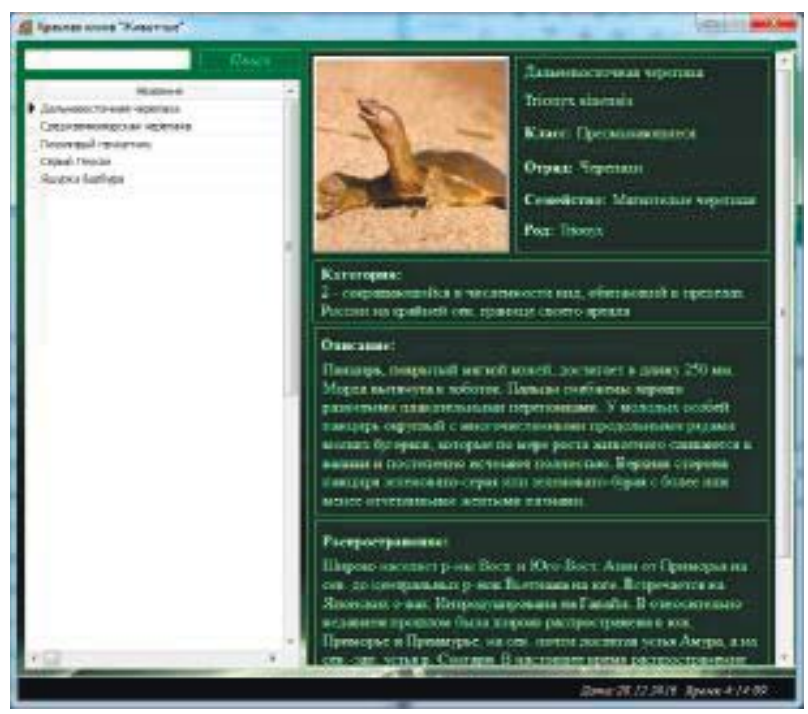

Рис. 5. Животные

«Справка» при нажатии на данную кнопку появится новое окно (рисунок 8) , в котором пользователь сможет, получить справку, о том, что выбранное им животное занесено в красную книгу.

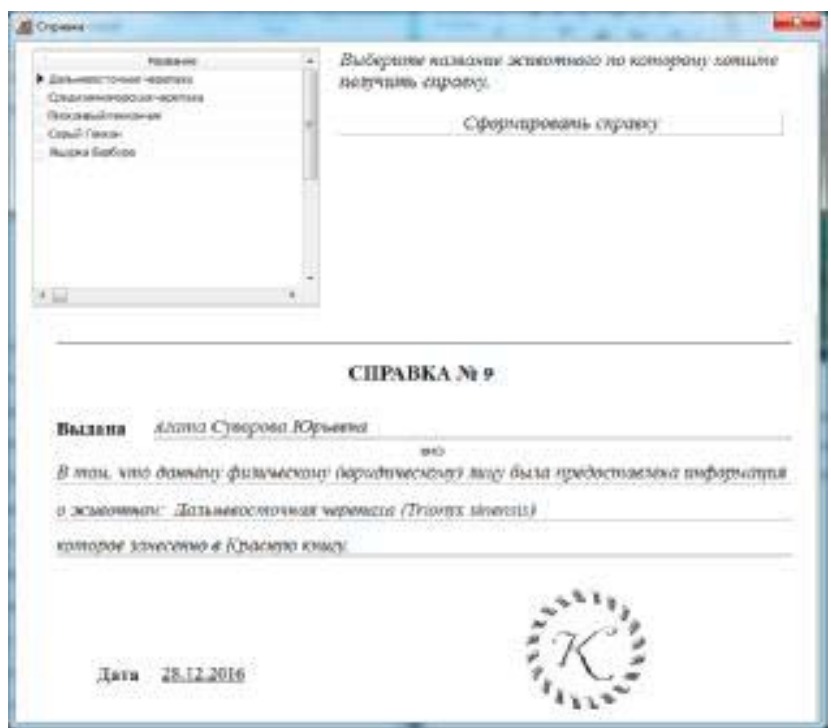

Рис. 6. Справка

В дальнейшем разработанную программу можно усовершенствовать. В приложение можно добавить функцию печати справки, а так же можно реализовать процедуру выгрузки необходимой информации в отдельный файл с возможностью вывода на печать.

\section{Список литературы:}

1. Красная Книга России [Электронный ресурс] // URL: http://biodat.ru/db/rb/ru (дата обращения: 25.02.2017).

2. Embarcadero RAD Studio 2010 [Электронный ресурс] // Программирование Паскаль (Pascal) и Делфи (Delphi) // URL: http://delphi-box.ru/embarcadero-rad-studio2010.html (дата обращения: 15.02.2017). 